\title{
Cancer risk in DES daughters
}

\author{
Janneke Verloop • Flora E. van Leeuwen • \\ Theo J. M. Helmerhorst • Hester H. van Boven • \\ Matti A. Rookus
}

Received: 19 October 2009/Accepted: 10 February 2010/Published online: 4 March 2010

(C) The Author(s) 2010. This article is published with open access at Springerlink.com

\begin{abstract}
Objective We examined long-term risk of cancer in women exposed to diethylstilbestrol (DES) in utero.

Methods A total of 12,091 DES-exposed women in the Netherlands were followed prospectively from December 1992 till June 2008. Cancer incidence was assessed through linkage with the Dutch pathology database (PALGA) and the Netherlands Cancer Registry and compared with the Dutch female population.

Results A total of 348 medically verified cancers occurred; median age at end of follow-up was 44.0 years. No overall increased risk of cancer was found (standardized incidence ratio $[\mathrm{SIR}]=1.01 ; 95 \%$ confidence interval $[C I]=0.91,1.13)$. The risk of clear cell adenocarcinoma of the vagina and cervix (CCA) was statistically significantly increased $(\mathrm{SIR}=24.23 ; 95 \% \mathrm{CI}=8.89,52.74)$; the elevated risk persisted above 40 years of age. The risk of melanoma diagnosed before age 40 was increased $(\mathrm{SIR}=1.59 ; 95 \% \mathrm{CI}=1.08,2.26)$. No excess risks were found for other sites, including breast cancer.
\end{abstract}

Electronic supplementary material The online version of this article (doi:10.1007/s10552-010-9526-5) contains supplementary material, which is available to authorized users.

J. Verloop · F. E. van Leeuwen · M. A. Rookus $(\bowtie)$

Department of Epidemiology, Netherlands Cancer Institute,

Plesmanlaan 121, 1066 CX Amsterdam, The Netherlands

e-mail: m.rookus@nki.nl

T. J. M. Helmerhorst

Department of Obstetrics and Gynaecology, Erasmus MC,

University Hospital Rotterdam, Rotterdam, The Netherlands

H. H. van Boven

Department of Pathology, Netherlands Cancer Institute,

Amsterdam, The Netherlands
Conclusions Except for an elevated risk of CCA, persisting at older ages, and an increased risk of melanoma at young ages, we found no increased risk of cancer. Longer follow-up is warranted to examine cancer risk at ages when cancer occurs more frequently.

Keywords Diethylstilbestrol - Estrogens - Prenatal exposure delayed effects $\cdot$ Adverse effects $\cdot$ Cancer risk

\section{Introduction}

Diethylstilbestrol (DES) is a synthetic estrogen that was prescribed to several millions of pregnant women worldwide from the late 1940s to the early 1970s, in order to prevent miscarriages and other pregnancy complications [1, 2]. Among women exposed prenatally to the drug, several adverse health effects have been observed before age 30 , such as clear cell adenocarcinoma of the vagina and cervix (CCA) and reproductive tract abnormalities [3, 4]. These findings raised concern about potential other long-term health effects. In prenatally DES-exposed mice, similar genital tract alterations were found, including vaginal adenocarcinomas and adenosis [5]. In addition, DES-exposed mice developed uterine tumors [5].

Molecular mechanisms are still unclear, but results from animal studies suggest that DES exposure in utero might lead to a persistent overexpression of protooncogenes that are associated with increased proliferation (c-jun, c-fos, c-myc) or decreased apoptosis (bcl-2, bcl-x), resulting in unregulated cell growth and carcinogenesis (see review [6]). In addition, growth factor genes (like EGF, TGF- $\alpha$ ) have been shown to be overexpressed after in utero exposure to DES [7]. Also other estrogen responsive genes, like the lactoferrin gene, are induced by DES exposure (see review [6]). 
In humans, long-term cancer risk in DES daughters has only been studied in the National Cancer Institute (NCI) DES Follow-up Study [8]. With a median age of 49 at the end of follow-up, this study revealed no excess risks for cancer except for CCA and breast cancer after age 40 . Risks for squamous cell cervical cancer and melanoma could not be evaluated, because agreement between selfreported cancers and medical verification was poor and medical verification data were incomplete.

We report on the first European study of cancer risk in a large cohort of 12,091 DES-daughters, with long-term and complete follow-up. Cancer incidence was ascertained through linkages with the population-based Netherlands Cancer Registry (NCR) and the Dutch nationwide pathology database (PALGA) [9]. Since all cancers were medically verified, this study is the first one to report on the risks of squamous cell cervical cancer and melanoma.

\section{Materials and methods}

\section{Study population}

The DES-net project is a nationwide prospective follow-up study of 12,091 Dutch DES daughters, identified through the registry of the Netherlands DES Center. This registry was established in 1992, in order to deal with future health claims. All DES daughters were advised to register, both individuals with and without health problems at time of registration. Documented DES exposure was not necessary at the time of registration. Median age of the DES daughters at time of registration was 29 .

From March 2000 till December 2004, 13,113 women received a 16-page mailed questionnaire on risk factors for hormone-related cancers and medical history (Fig. 1). The questionnaire included an informed consent form to grant permission for abstracting data from their medical records and population-based disease registries. Also, women were asked to provide a copy of their documented DES exposure. In case no copy was available, the mother was asked to give permission to have her medical record traced by the researchers. Non-responders were sent a reminder after 2 months and a second reminder after 6 months. The final response rate to the questionnaire was $60 \%$.

The study was approved by the Medical Ethical Committee of the Netherlands Cancer Institute and the Surveillance Committees of PALGA and the NCR.

Assessment of cancer incidence and death

Cancer incidence was assessed through linkage with PALGA and NCR, which both have nationwide coverage since 1989 and 1991, respectively. The Surveillance Committees

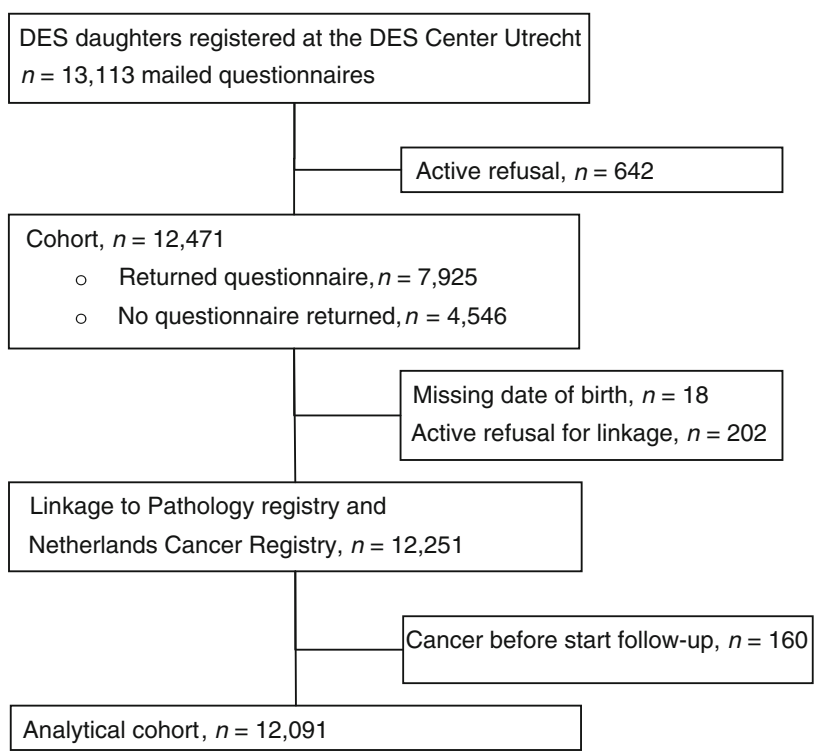

Fig. 1 Response rates of eligible cohort of DES daughters

granted us permission to link both responders and nonresponders under strict privacy procedures, while we excluded 202 women who had refused. Linkage information was complete for 12,251 women (Fig. 1). After linkage, information was provided on date of diagnosis, type of tumor, and morphology. All tumors were coded according to the International Classification for Diseases, 10th revision. Vital status was obtained by linkage with the Dutch Office of Death Registry (CBG), updated till October 2007. A total of 128 women died during follow-up, of whom 54 died of cancer.

Classification of DES exposure for women with questionnaire data

Documented DES exposure was available for 881 subjects (Table 2). For the majority of our subjects, no documented DES exposure was available. For sensitivity analyses, we used as surrogates of DES exposure medically verified DES-related reproductive tract abnormalities (such as adenosis, squamous cell metaplasia occurring in the vagina or in an extensive area of the portio (more than 75\%), cox comb, vaginal ridges, T-shaped uterus). Adenosis and squamous cell metaplasia were ascertained by colposcopy.

Furthermore, we assigned women to 'suspected DESexposed' in case women reported in the questionnaire threatened or prior bleeding or prior pregnancy loss as indications for DES usage by their mother, since it has been observed that these indications are strongly associated with documented DES exposure [10]. Finally, we distinguished a category of women who had been frequently screened ( 3 or more cervical Pap smears before age 30 or 2 or more vaginal smears before age 50), with exclusion of diagnostic smears. Pap smears before age 30 occur very infrequently in the 
general population as the Dutch national screening surveillance program starts at age 30. In DES daughters, however, Pap smears before age 30 do occur since they are advised to have a yearly gynecological exam during the first 5 years of DES surveillance, including vaginal and cervical smears. Therefore, having had 3 or more Pap smears before age 30 was considered a valid indicator of suspected DES exposure in the Netherlands.

Validation of DES exposure for women

with questionnaire data

For 115 subjects, we compared self-reported DES exposure with the information in prenatal records in four hospitals with preserved historical medical archives.

\section{Statistical analyses}

Women with cancer diagnosed before the start of follow-up $(n=160)$ were excluded from analyses, among whom were 53 patients with CCA. A total of 12,091 women were included in the analyses. Follow-up started at the date of registration at the DES Center and ended on June 30, 2008, the date of first cancer diagnosis, or death, whichever came first. We excluded 2 second primary tumors that were probably related to cancer treatment ( 1 squamous cell cervical cancer after treatment for cervical adenocarcinoma; 1 squamous cell vaginal cancer after treatment for vaginal adenocarcinoma).

Standardized Incidence Ratio's (SIRs) were calculated to compare the observed cases in our study with the expected number in the general population, based on age-, sex-, and calendar period-specific incidence rates from the NCR. The 95\% confidence intervals (95\% CI) were calculated assuming a Poisson distribution [11].

We also calculated risks for women stratified according to the availability of questionnaire data, age, type of DES confirmation, medical indication for DES use, parity, maternal age of DES mother, education, and duration of index pregnancy.

As reference for the stage distribution of melanoma, we used the age-specific stage distribution in the general female population in the period 2003-2007.

To test for heterogeneity in the SIRs between strata, the chi-square distribution was applied [11].

We used SPSS statistical software (SPSS Inc., Chicago, IL).

\section{Results}

The majority of the DES daughters were born between 1961 and 1970, with no differences between women with
Table 1 Baseline characteristics of Dutch DES daughters $(n=12,091)$ according to type of response

\begin{tabular}{|c|c|c|c|c|}
\hline & \multicolumn{2}{|l|}{$\begin{array}{l}\text { Questionnaire } \\
(n=7,589)\end{array}$} & \multicolumn{2}{|c|}{$\begin{array}{l}\text { Without questionnaire } \\
(n=4,502)\end{array}$} \\
\hline & No. of women & $\%$ & No. of women & $\%$ \\
\hline \multicolumn{5}{|l|}{ Year of birth } \\
\hline$\leq 1955$ & 968 & 13 & 557 & 12 \\
\hline $1956-1960$ & 1,731 & 23 & 840 & 19 \\
\hline 1961-1965 & 1,852 & 24 & 1,095 & 24 \\
\hline 1966-1970 & 2,139 & 28 & 1,280 & 28 \\
\hline$>1970$ & 899 & 12 & 730 & 16 \\
\hline \multicolumn{5}{|c|}{ Age at end of follow-up } \\
\hline$<40$ & 2,103 & 28 & 1,425 & 32 \\
\hline $40-49$ & 3,853 & 51 & 2,231 & 50 \\
\hline $50+$ & 1,633 & 22 & 846 & 19 \\
\hline \multicolumn{5}{|c|}{ Year of registration } \\
\hline 1992 & 7,052 & 93 & 4,139 & 92 \\
\hline 1993-1995 & 304 & 4 & 244 & 5 \\
\hline 1996-2000 & 200 & 3 & 65 & 1 \\
\hline 2001-2005 & 33 & 0 & 54 & 1 \\
\hline
\end{tabular}

and without a questionnaire (Table 1). Ninety-three percent of the women registered in 1992. The median age at the end of follow-up was 44.3 years in the questionnaire group and 43.3 years in the group without questionnaire.

Twelve percent of the DES daughters with questionnaire data had documented DES exposure, 22\% had medically verified DES-associated reproductive tract abnormalities, and $26 \%$ had a history of frequent vaginal or cervical screening (Table 2). Habitual abortion was the most frequently self-reported medical indication for DES usage by the mother $(50 \%)$, followed by threatened abortion $(25 \%)$ or the combination of both $(17 \%)$. DES daughters were more often highly educated (college or university) compared to women in the Dutch female population (38 and $25 \%$, respectively, reference data not in the table). Twentyeight percent of the women had overweight or were obese (compared to $34 \%$ in the general female population). Thirty-three percent of the DES daughters above 40 years of age (as a proxy for the end of a woman's fertile lifespan) were nulliparous, compared to $17 \%$ of the Dutch population in the same age category (reference data not shown).

Overall cancer risk was not increased in DES daughters compared to the general population (SIR $=1.01 ; 95 \%$ $\mathrm{CI}=0.91,1.13$ ) (Table 3 ). The SIR for CCA of the vagina and cervix was statistically significantly increased $(\mathrm{SIR}=24.23 ; 95 \% \mathrm{CI}=8.89,52.74)$. No association for breast cancer was observed ( $\mathrm{SIR}=1.05 ; 95 \% \mathrm{CI}=0.90$, 1.23). The risk of squamous cell cancer located in the vagina or cervix was non-significantly decreased compared to the general population $(\mathrm{SIR}=0.64 ; 95 \% \mathrm{CI}=0.31$, 
Table 2 Baseline characteristics of DES daughters with questionnaire data

\begin{tabular}{|c|c|c|}
\hline & $\begin{array}{l}\text { Questionnaire } \\
(n=7,589)\end{array}$ & \\
\hline & No. of women & $\%$ \\
\hline \multicolumn{3}{|l|}{ DES confirmation } \\
\hline Medical file mother & 881 & 12 \\
\hline DES-related reproductive tract abnormalities & 1,648 & 22 \\
\hline $\begin{array}{l}\text { History of frequent } \mathrm{t}^{\mathrm{a}} \text { vaginal screening (before } \\
\text { age 50) or frequent }{ }^{\mathrm{a}} \text { cervical screening (before } \\
\text { age 30) }\end{array}$ & 1,983 & 26 \\
\hline No information available & 3,077 & \\
\hline \multicolumn{3}{|l|}{ Medical indication DES use mother } \\
\hline Both threatened and habitual abortion & 1,310 & 17 \\
\hline Threatened abortion only & 1,902 & 25 \\
\hline Habitual abortion only & 3,827 & $\pi$ \\
\hline Diabetes & 9 & \\
\hline Premature delivery, uterus problems & 34 & \\
\hline Other problems index pregnancy & 36 & \\
\hline History of pregnancy problems (other than abortion) & 153 & \\
\hline No obvious medical indication (prevention) & 94 & \\
\hline Unknown & 224 & \\
\hline \multicolumn{3}{|l|}{ Highest educational level } \\
\hline Primary school & 952 & 13 \\
\hline Secondary school & 3,617 & 48 \\
\hline College or university & 2,846 & 3 \\
\hline Unknown or missing & 174 & \\
\hline \multicolumn{3}{|l|}{ Body mass index, $\mathrm{kg} / \mathrm{m}^{2}$} \\
\hline$<20$ & 939 & 12 \\
\hline $20-24$ & 4,336 & 57 \\
\hline $25-29$ & 1,571 & 21 \\
\hline $30+$ & 557 & \\
\hline Unknown or missing & 186 & \\
\hline \multicolumn{3}{|l|}{ Parity ${ }^{\mathrm{b}}$} \\
\hline Yes & 1,360 & 66 \\
\hline No & 680 & 33 \\
\hline Unknown or missing & 34 & \\
\hline \multicolumn{3}{|l|}{ Maternal age (DES mother) } \\
\hline$<25$ & 1,141 & 15 \\
\hline $25-29$ & 2,604 & 34 \\
\hline $30-34$ & 2,193 & 29 \\
\hline $35+$ & 1,481 & 20 \\
\hline Unknown or missing & 170 & . \\
\hline
\end{tabular}

${ }^{a}$ Frequency of screening: two or more vaginal smears before age 50 or three or more cervical smears before age 30

b Among $n=2,074$ women older than 40 at time filling in the questionnaire

1.17). A significantly decreased risk was observed for lung cancer (SIR $=0.54 ; 95 \% \mathrm{CI}=0.27,0.96)$. No statistically significant findings were observed for other types of cancer. Similar cancer risks were seen in the subgroup of women with questionnaire data, except for a statistically significantly increased risk of cancer of the placenta (chorioncarcinoma) $(\mathrm{SIR}=11.41 ; 95 \% \mathrm{CI}=1.38,41.21)$ based on two cases. Risk was similar when we restricted the analyses to women with questionnaire data.

Within the group with questionnaire data, we were able to stratify according to confirmation of DES exposure (Table 4). The risks of CCA and vagina cancer were strongly elevated in all strata, though the SIR estimates for CCA was highest in the group confirmed by medical file $(\mathrm{SIR}=109.9 ; 95 \% \mathrm{CI}=12.3,396.79)$. The observed events of melanoma occurred in two strata and both showed similarly elevated SIRs. The risk for breast cancer was highest in the group with the lowest level of DES confirmation ( $\mathrm{SIR}=1.94 ; 95 \% \mathrm{CI}=0.93,3.57)$.

When we compared self-reported DES exposure with the information in prenatal records DES exposure was confirmed in 53 records of the 70 subjects (76\%), in 15 records neither DES nor other medication was recorded $(21 \%)$, and in 2 records another drug was mentioned (3\%) (Table 5).

Table 6 shows the association between DES exposure and risk of cancer stratified according to age at diagnosis. The risk of melanoma, diagnosed before age 40 , was statistically significantly increased $\quad(\mathrm{SIR}=1.59 ; \quad 95 \%$ $\mathrm{CI}=1.08,2.26$ ), but no increased risk after age 40 was detected (Table 6). The elevated risk at young ages did not seem to be attributable to detection bias, because the stage distribution was comparable with the general population $\left(\chi^{2} 1.94, p=0.75\right.$ and $\chi^{2} 5.59, p=0.23$, for ages $<40$ and $40+$, respectively) (Table 1 , supplement). CCA risk remained elevated at ages above $40(\mathrm{SIR}=32.89 ; 95 \%$ $\mathrm{CI}=3.98,118.76$ ). The decrease in lung cancer risk was most pronounced above 40 years of age, but based on eight cases only. For the other types of cancer, no differences between age strata were observed.

Four CCA patients were diagnosed in the age category 30-39 years and two CCA patients between the ages of 4049 years (Table 2, supplement). The incidence rates for CCA in women aged 30-39 and 40-49 were 0.05 and 0.04 per 1,000 women-years, respectively. Among the five CCA patients with medical information, one case had a confirmed history of adenosis. One patient had a younger sister with CCA (no participant, diagnosed at age 23 and deceased at age 25). All CCA patients diagnosed prospectively were still alive at the end of our follow-up.

\section{Discussion}

In this first European cohort study of cancer risk in DES daughters, no overall increased cancer risk was observed 
Table 3 Risk of cancer among DES daughters, for all women and women with questionnaire data only ${ }^{\mathrm{a}}$

\begin{tabular}{|c|c|c|c|c|c|c|c|c|}
\hline \multirow[t]{2}{*}{ Type of cancer } & \multicolumn{4}{|c|}{$\begin{array}{l}\text { All participants } \\
n=12,091 \\
180,941 \text { women-years }\end{array}$} & \multicolumn{4}{|c|}{$\begin{array}{l}\text { With questionnaire data only } \\
n=7,589 \\
113,845 \text { women-years }\end{array}$} \\
\hline & Obs & Exp & SIR & $95 \% \mathrm{CI}$ & Obs & Exp & SIR & $95 \% \mathrm{CI}$ \\
\hline Total cancer ${ }^{b, c}$ & 348 & 343.3 & 1.01 & $0.91-1.13$ & 217 & 219.8 & 0.99 & $0.86-1.13$ \\
\hline Breast & 165 & 156.5 & 1.05 & $0.90-1.23$ & 112 & 100.7 & 1.11 & $0.92-1.34$ \\
\hline Cervix (all morphologies) & 15 & 20.4 & 0.74 & $0.41-1.21$ & 10 & 13.0 & 0.77 & $0.37-1.42$ \\
\hline Vagina (all morphologies) & 6 & 0.4 & 16.42 & $6.02-35.74$ & 5 & 0.2 & 21.51 & $6.98-50.21$ \\
\hline Vagina and cervix & 21 & 20.8 & 1.01 & $0.63-1.55$ & 15 & 13.2 & 1.13 & $0.64-1.87$ \\
\hline Clear cell adenocarcinoma & 6 & 0.3 & 24.23 & $8.89-52.74$ & 5 & 0.2 & 32.02 & $10.38-74.71$ \\
\hline Squamous cell carcinoma & 10 & 15.7 & 0.64 & $0.31-1.17$ & 7 & 10.0 & 0.70 & $0.28-1.44$ \\
\hline Adenocarcinoma & 4 & 3.8 & 1.06 & $0.29-2.71$ & 3 & 2.4 & 1.25 & $0.26-3.65$ \\
\hline Adenosquamous carcinoma & 1 & 0.7 & 1.39 & $0.04-7.76$ & 0 & 0.5 & & \\
\hline Vulva & 2 & 1.6 & 1.27 & $0.15-4.59$ & 1 & 1.0 & 0.99 & $0.03-5.51$ \\
\hline Corpus uteri & 9 & 7.1 & 1.27 & $0.58-2.41$ & 4 & 4.5 & 0.88 & $0.24-2.26$ \\
\hline Ovary $^{c}$ & 10 & 10.8 & 0.92 & $0.44-1.7$ & 6 & 6.9 & 0.87 & $0.32-1.88$ \\
\hline Placenta & 2 & 0.3 & 7.10 & $0.86-25.64$ & 2 & 0.2 & 11.41 & $1.38-41.21$ \\
\hline Lung $^{c}$ & 11 & 20.4 & 0.54 & $0.27-0.96$ & 5 & 13.2 & 0.38 & $0.12-0.89$ \\
\hline Melanoma $^{c}$ & 48 & 35.3 & 1.36 & $1.00-1.8$ & 26 & 22.4 & 1.16 & $0.76-1.7$ \\
\hline Colon, rectum, anus & 15 & 17.6 & 0.85 & $0.48-1.41$ & 9 & 11.2 & 0.80 & $0.37-1.53$ \\
\hline Thyroid & 6 & 6.5 & 0.92 & $0.34-2.01$ & 4 & 4.11 & 0.97 & $0.26-2.49$ \\
\hline Hodgkin lymphoma & 3 & 3.6 & 0.84 & $0.17-2.47$ & 1 & 2.2 & 0.45 & $0.01-2.53$ \\
\hline $\begin{array}{l}\text { Non-Hodgkin lymphoma, immunoproliferative } \\
\text { disease }\end{array}$ & 8 & 8.3 & 0.96 & $0.42-1.9$ & 6 & 5.3 & 1.13 & $0.42-2.47$ \\
\hline Brain & 8 & 6.3 & 1.28 & $0.55-2.52$ & 5 & 4.0 & 1.26 & $0.41-2.94$ \\
\hline Leukemia & 3 & 5.7 & 0.52 & $0.11-1.53$ & 3 & 3.6 & 0.83 & $0.17-2.42$ \\
\hline
\end{tabular}

${ }^{a}$ SIR, Standardized incidence ratio, defined as observed number of cancers compared to the expected number of cancers in the general population with the same age; $95 \% \mathrm{CI}=95 \%$ confidence interval based on a Poisson distribution, obs $=$ observed number of cases; $\exp =$ expected number of cases

b 27 cancers included in total cancer rate but not included in table: Lip (1), Tongue (1), Mouth (2), Salivary glands (1), Stomach (3), Anus (1), Pancreas (2), Larynx (1), Trachea (1), Sarcoma (2), Skin, squamous cell (9), Mesothelioma (1), Kidney (1), Bladder (2), Eye (1), Central Nervous System (1), Plasma cell tumor (1), Unknown or ill defined (6)

${ }^{c}$ Eight secondary tumors were included: Lung (2), Sarcoma (1), Melanoma (1), Skin, squamous cell (1), Ovary (1), Central nervous system (1), Non-Hodgkin lymphoma (1)

compared to the general population. The risk of CCA remained increased after age 40. Neither overall breast cancer risk was increased, nor risk above age 40 . We found an elevated risk of melanoma before age 40 . The risk of lung cancer was decreased.

A unique feature of this study is the large study size and the almost complete long-term follow-up for cancer. Also, all cancers were medically verified. However, a drawback of our study is that the majority of participants had no documented DES exposure. Nevertheless, we think that the assumption is justified that the majority of our subjects was indeed exposed to DES, for the following reasons. First, in our validation study self-reported DES exposure was confirmed in 53 prenatal records (76\%), whereas in 15 records neither DES nor any other medication was recorded (21\%). It is still possible that in the latter cases DES was prescribed by the general practitioner rather than the gynecologist. In the Netherlands, pregnancies have always been under the surveillance of general practitioners or midwives. DES was also prescribed by general practitioners but their records are notoriously hard to trace. Therefore, we estimate that the misclassification with regard to DES exposure is probably higher than $3 \%$ but certainly lower than $24 \%$. Second, stratification according to levels of confirmation of DES exposure did not result in different conclusions (Table 4), whereas more uncertainty about DES exposure might have led to more bias to the null. Finally, the proportion of women doubting their DES exposure was higher among women who did not respond to the questionnaire. Although, in general, the SIRs were slightly higher in the questionnaire group, these differences were not statistically significant (Table 3 ). 


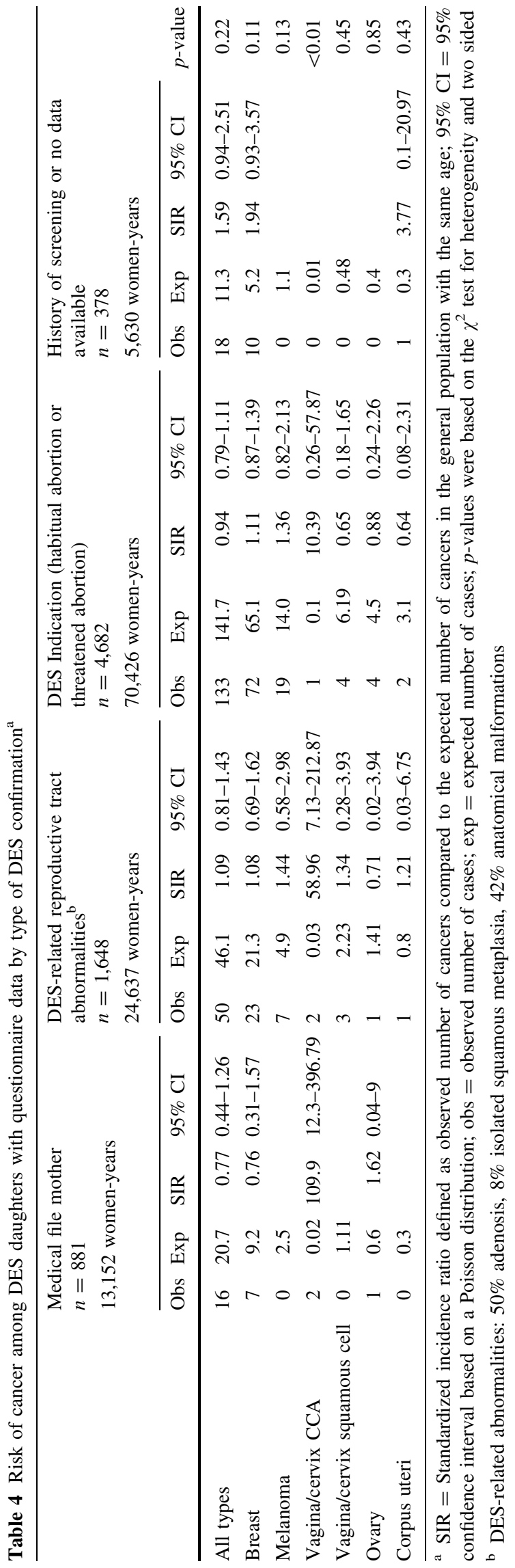

Furthermore, women may have registered at the Netherlands DES Center because of gynecological complaints, although women without health problems at time of registration were especially encouraged to register. Since we prospectively followed all women from time of registration, all cancer diagnoses prior to registration were not included in our analysis. However, our results might still be biased if health problems were related to future cancer risk (both bias to or away from zero). In a sensitivity analysis, we excluded the first follow-up years in the analyses, to adjust for signs and symptoms of disease at time of registration, with similar results.

It is possible that women enrolled into our cohort differ from the background population of DES daughters. For instance, with respect to breast cancer nulliparity might cause such selection bias. As expected, the proportion of nulliparous women in our cohort was higher than in the general population (33 vs. $17 \%$, respectively) due to a higher prevalence of subfertility among DES daughters compared to the general population [4]. However, if women registered because of subfertility problems (median age at registration was 29.1 years), the proportion of nulliparous women might be too high, and as a result the risk of breast cancer in our cohort might be underestimated during premenopausal years (assuming that the risk of breast cancer is transiently increased after childbirth, [12]), and overestimated during postmenopausal years. To examine whether the SIR of 1.11 (95\% CI: 0.92-1.34) for breast cancer overall was due to nulliparity, we conducted partially stratified analyses comparing strata of parous and nulliparous women with the total reference group. The SIR for breast cancer was 1.19 (95\% CI: 0.93-1.49) for parous and 0.96 (95\% CI: 0.66-1.35) for nulliparous women (data not shown), suggesting that a higher frequency of nulliparity did not explain our results.

Another limitation of our study design is the lack of an internal comparison group, which prevented us from adjusting for several risk factors for cancer. The stratified analyses among women with questionnaires showed no statistically significant differences in cancer risk between strata of parity, maternal age of DES mother, education, and duration of index pregnancy (data not shown). However, residual confounding might still occur, since the reference group could not be stratified by any confounder except age and birth cohort. In spite of this, our analyses suggest that these effects are small.

In contrast to our study, DES exposure in the NCI DES follow-up study was completely verified. However, incident cancer cases were obtained by mailed questionnaires and medical record retrieval for confirmation of selfreported cancer was incomplete.

With the limitations of our study kept in mind, we found a highly increased risk of CCA, although somewhat lower than 
Table 5 Validation of self-reported DES exposure in four hospitals with preserved historical medical archives

Mother self-reported DES exposure, $n=115$

\begin{tabular}{lcc}
\hline No. medical file available & 45 & $31 \%$ \\
Medical file mother available & 70 & $61 \%$ \\
DES exposure confirmed in medical file & \\
Yes & 53 & $76 \%$ \\
No & 15 & $21 \%$ \\
Other medicine reported & 2 & $3 \%$ \\
\hline
\end{tabular}

found in the NCI DES follow-up study (SIR $=24.23 ; 95 \%$ $\mathrm{CI}=6.02,35.74$ and $\mathrm{SIR}=39.0 ; 95 \% \mathrm{CI}=15,104$, respectively) [8]. Our SIR estimate does not apply to ages below 30, which might partly explain the lower estimate. The CCA incidence rate of 0.05 per 1,000 exposed women aged 30-39 (based on four cases) was similar to the incidence rate of 0.03 per 1,000 in the NCI study (based on one case in the same age range) [8]. Our study shows that the CCA risk remained increased after age $40 \quad(\mathrm{SIR}=32.89 ; 95 \%$ $\mathrm{CI}=3.98,118.76$, incidence rate of 0.04 per 1,000 , based on two cases). Recently, DES-associated CCA patients up to age 55 have been added to the Registry for Research on Hormonal Transplacental Carcinogenesis, and a possible increase in incidence at age $\geq 40$ years has been suggested (http://obgyn. bsd.uchicago.edu/registry.html). The cumulative incidence rate for exposed women ages 30-44 years in our study was 0.8 per 1,000 women. Combined with the cumulative incidence rate in the Dutch CCA registry of 1.5 per 1,000 women before age 30 (personal communication Jos van Dijck,
Comprehensive Cancer Centre East), we calculated an absolute risk of 2.3 CCA cases per 1,000 DES daughters by age 44 (compared to 1.6 per 1,000 DES daughters by age 39 in the NCI DES follow-up study).

Trichopoulos et al. hypothesized that prenatal factors associated with high endogenous estrogen levels in utero might increase the risk of breast cancer [13]. In the NCI study, the overall risk for breast cancer was not increased, comparing DES exposed to unexposed women. However, at ages $\geq 40$ and $\geq 50$ years risks were significantly increased (incidence rate ratio $(\mathrm{IRR})=1.91 ; 95 \%$ $\mathrm{CI}=1.09,3.33$ and $\mathrm{IRR}=3.00 ; 95 \% \mathrm{CI}=1.01,8.98$, respectively) [14]. The increased risks for breast cancer attenuated when general population data (SEER) were used as reference, possibly explained by the lower body mass index of the study population (both exposed and unexposed). We used the general population as reference and found no increased breast cancer risk neither overall, nor above age $40(\mathrm{SIR}=1.05 ; 95 \% \mathrm{CI}=0.90,1.23$ and $\mathrm{SIR}=1.09 ; 95 \% \mathrm{CI}=0.91,1.31$, respectively). Our DES daughters might differ from the general population with respect to breast cancer risk factors for which we could not adjust. However, stratification for educational level, parity, and maternal age at birth did not alter our results. Another possible explanation for the inconsistent findings between our study and the NCI study is chance, because the number of cases was relatively small in the older age categories. Also, the misclassification of DES exposure in our study might have attenuated the risk.

Melanoma risk was statistically significantly increased among women ages $<40$ years. In addition, the risk was

Table 6 Risk of cancer among DES daughters by age at diagnosis ${ }^{\mathrm{a}}$

\begin{tabular}{|c|c|c|c|c|c|c|c|c|}
\hline \multirow[t]{2}{*}{ Type of cancer } & \multicolumn{4}{|c|}{$\begin{array}{l}\text { Attained age }<40 \text { years of age } \\
119,394 \text { women-years }\end{array}$} & \multicolumn{4}{|c|}{$\begin{array}{l}\text { Attained age } \geq 40 \text { years of age } \\
61,547 \text { women-years }\end{array}$} \\
\hline & Obs & Exp & SIR & $95 \% \mathrm{CI}$ & Obs & Exp & SIR & $95 \% \mathrm{CI}$ \\
\hline All types & 124 & 118.8 & 1.04 & $0.87-1.24$ & 224 & 224.5 & 1.00 & $0.87-1.14$ \\
\hline Breast & 42 & 44.0 & 0.95 & $0.69-1.29$ & 123 & 112.6 & 1.09 & $0.91-1.31$ \\
\hline Melanoma & 31 & 19.5 & 1.59 & $1.08-2.26$ & 17 & 15.8 & 1.08 & $0.63-1.72$ \\
\hline Vagina (all morph) & 3 & 0.2 & 18.02 & $3.72-52.65$ & 3 & 0.2 & 15.08 & $3.11-44.07$ \\
\hline Cervix (all morph) & 9 & 12.95 & 0.69 & $0.32-1.32$ & 6 & 7.4 & 0.81 & $0.30-1.76$ \\
\hline \multicolumn{9}{|l|}{ Vagina and cervix } \\
\hline CCA & 4 & 0.2 & 21.41 & $5.81-54.82$ & 2 & 0.1 & 32.89 & $3.98-118.76$ \\
\hline Squamous cell & 6 & 9.9 & 0.60 & $0.22-1.31$ & 4 & 5.8 & 0.70 & $0.19-1.78$ \\
\hline Placenta & 2 & 0.3 & 7.75 & $0.94-27.99$ & 0 & 0.02 & & \\
\hline Lung & 3 & 3.2 & 0.94 & $0.19-2.75$ & 8 & 17.2 & 0.46 & $0.20-0.92$ \\
\hline Ovary & 4 & 3.6 & 1.13 & $0.31-2.89$ & 6 & 7.3 & 0.82 & $0.30-1.79$ \\
\hline Corpus uteri & 3 & 0.9 & 3.22 & $0.66-9.41$ & 6 & 6.2 & 0.97 & $0.36-2.12$ \\
\hline
\end{tabular}

${ }^{a}$ SIR = Standardized incidence ratio defined as observed number of cancers compared to the expected number of cancers in the general population with the same age; $95 \% \mathrm{CI}=95 \%$ confidence interval based on a Poisson distribution; obs = observed number of cases; $\exp =$ expected number of cases 
higher in the total cohort than in the group with questionnaire data. Possibly, some survival bias may be present in the questionnaire group as not all melanoma cases might have survived long enough to be able to participate to the questionnaire. In the NCI study, melanoma risk could not be evaluated because medical verification of this cancer, and cervical cancer, was incomplete. Sun exposure and skin type are considered to be main risk factors, while the role of reproductive and hormonal factors is controversial [15]. It has been suggested that low parity is associated with an increased risk [16], but we could not confirm that in our study (data not shown). Additionally, although this is only circumstantial evidence, the immune system might be involved. Suppression of immune response in transplantation patients who receive long-term immunosuppression therapy has been associated with a higher risk of melanoma [17]. Some studies suggested that DES daughters might be at higher risk of developing autoimmune diseases [18] or have an enhanced immune response to different mitogens $[19,20]$. However, the relevance of autoimmune diseases to melanoma risk is unclear and an enhanced immune response would probably not be associated with an increased risk of melanoma. Also it is unlikely that surveillance bias plays a major role, as the stage distribution of melanoma did not differ between our subjects and the general population. Since this is the first time that melanoma risk was found to be increased in DES daughters, this result needs to be confirmed by other studies.

The risk of squamous cell cervical cancer was nonsignificantly decreased. This is likely due to the high screening rate among DES daughters, leading to enhanced detection of precancerous lesions of the cervix. In an earlier publication, we reported on an increased prevalence ratio (PR) of squamous cell cervical cancer among DES daughters $(\mathrm{PR}=5.4 ; 95 \% \mathrm{CI}=2.8,9.5)$ [21]. However, selection bias could not be ruled out. In the NCI study, medical verification for cervical cancer was incomplete and no valid risk estimates were available [22]. When evaluating cervical cancer risk, one should also take the number of pre-invasive cervical lesions into account [23].

In our study, one incident and two prevalent cases of invasive squamous cell vaginal cancer occurred, while 0.2 case was expected. All cases were reviewed by our pathologist $(\mathrm{HvB})$. Assuming that these three cases were the only ones occurring among DES-exposed women in the Netherlands (alive at the time of registration), we calculated a life-time prevalence of 3 cases per 40,000 exposed women $(7.5$ per 100,000). This prevalence rate was 4 times as high as the prevalence rate (20-year period) in the general population in the same age category (1.8 prevalent cases per 100,000 women, region Comprehensive Cancer Centre Amsterdam). However, the estimated number of DES-exposed women in the Netherlands is rather uncertain and the number of cases is small.

The risk of lung cancer was statistically significantly reduced in our study. We did not collect information on smoking habits in our questionnaire. Therefore, we analyzed smoking behavior of 464 DES daughters that participated in a study on IVF treatment effects [24]. DES daughters smoked less cigarettes compared to the Dutch female population (source Statistics Netherlands), 13.2 and 15.9 cigarettes per day, respectively, which might explain our finding.

In conclusion, the results of our study are generally reassuring except for CCA, with a risk increase persisting at older ages. The slightly elevated risk of melanoma before age 40 is remarkable, but needs to be confirmed by other studies. We did not confirm the increased risk of breast cancer at older ages, as suggested in the NCI DES Follow-up study. Since most DES daughters in our cohort are still relatively young (44.0 years), longer follow-up is warranted to examine cancer risks at ages when cancer occurs more frequently.

Acknowledgments The authors would like to acknowledge the Netherlands Cancer Registry (in particular Dr. O. Visser and Dr. J. A. A. M. van Dijck) and PALGA (Drs. M. Casparie) for providing the follow-up data. The authors wish to thank Drs. W. Klokman for the use of his person year analyses program and Ir. T. M. Mooij for assistance with analyses. Furthermore, we would like to acknowledge for their help with data collection: M. Legdeur, O. van der Hel, M. Homs, A. van der Meij, E. Reisenstadt, P. Woerdeman, E. Staals, M. Das, W. Drenthen, I. van Bergen, M. Rueter, J. van der Swaluw, N. Goessens, H. Karim-Kos, A. Bruinsma, M. Zwaal, H. Kruizenga, J. Klein, J. Scherrenburg, R. Paulis, K. Karsenberg, S. de Jager, I. Bisschops, M. Simons, S. Dijkhuis, B. Huisman, K. Jeanson, H. Gerritsen, K. Bakhuis, E. Bosnajakovic, L. van Dussen, G. de Leeuw- Mantel. The authors would like to warmly thank the team of the DES Center team: Drs. M. Koster, M. Kattenburg, Drs. D. van der Brugge, J. Vellekoop, I. Faber and many other volunteers. The authors wish to thank for their cooperation with collecting data from the medical archives: Dr. J. E. G. M. Stoot, Drs. J. E. M. Degen, Dr. P. X. J. M. Bouckaert, Atrium Medical Center; Dr. P. J. Dörr,Medical Center Haaglanden, location: Westeinde; Dr. J. G. Aalders, Dr. A. G. J. van der Zee, University Medical Center Groningen; Drs. L. J. van Dam, Gelre hospitals,location: Juliana; Drs. J. van den Ham, Drs. J. H. Eggens, Rivierenland Hospital, Tiel and Dr. J. Koudstaal, University Medical Center, Utrecht.

Financial support This work was supported by The Dutch Cancer Society (grant number 2001-2426); The Netherlands Organization for Health Research and Development ZonMw; Sacha SwarttouwHijmans Foundation; Janivo Foundation; Mr. Paul de Gruyter Foundation; and Peterson Foundation.

Open Access This article is distributed under the terms of the Creative Commons Attribution Noncommercial License which permits any noncommercial use, distribution, and reproduction in any medium, provided the original author(s) and source are credited. 


\section{References}

1. Heinonen OP (1973) Diethylstilbestrol in pregnancy. Frequency of exposure and usage patterns. Cancer 31(3):573-577

2. Noller KL, Fish CR (1974) Diethylstilbestrol usage: its interesting past, important present, and questionable future. Med Clin North Am 58(4):793-810

3. Herbst AL, Ulfelder H, Poskanzer DC (1971) Adenocarcinoma of the vagina. Association of maternal stilbestrol therapy with tumor appearance in young women. N Engl J Med 284:878-881

4. Giusti RM, Iwamoto K, Hatch EE (1995) Diethylstilbestrol revisited: a review of the long-term health effects. [review] [113 refs]. Ann Intern Med 122:778-788

5. Newbold R (1995) Cellular and molecular effects of developmental exposure to diethylstilbestrol: implications for other environmental estrogens. Environ Health Perspect 103(Suppl 7):83-87

6. Newbold RR, Padilla-Banks E, Jefferson WN (2006) Adverse effects of the model environmental estrogen diethylstilbestrol are transmitted to subsequent generations. Endocrinology 147(6 Suppl):S11-S17

7. Sato T, Fukazawa Y, Ohta Y, Iguchi T (2004) Involvement of growth factors in induction of persistent proliferation of vaginal epithelium of mice exposed neonatally to diethylstilbestrol. Reprod Toxicol 19(1):43-51

8. Troisi R, Hatch EE, Titus-Ernstoff L et al (2007) Cancer risk in women prenatally exposed to diethylstilbestrol. Int $\mathrm{J}$ Cancer 121(2):356-360

9. Casparie M, Tiebosch AT, Burger G et al (2007) Pathology databanking and biobanking in The Netherlands, a central role for PALGA, the nationwide histopathology and cytopathology data network and archive. Cell Oncol 29(1):19-24

10. Sharp GB, Cole P, Anderson D, Herbst AL (1990) Clear cell adenocarcinoma of the lower genital tract. Correlation of mother's recall of diethylstilbestrol history with obstetrical records. Cancer 66:2215-2220

11. Breslow NE, Day NE (1987) Rates and rate standardization. In: Breslow NE, Day NE (eds) Statistical methods in cancer research. Volume II-The design and analysis of cohort studies. Oxford University Press, Oxford, pp 48-79
12. Lambe M, Hsieh C, Trichopoulos D, Ekbom A, Pavia M, Adami HO (1994) Transient increase in the risk of breast cancer after giving birth. N Engl J Med 331(1):5-9

13. Trichopoulos D (1990) Hypothesis: does breast cancer originate in utero? Lancet 335:939-940

14. Palmer JR, Wise LA, Hatch EE et al (2006) Prenatal diethylstilbestrol exposure and risk of breast cancer. Cancer Epidemiol Biomarkers Prev 15(8):1509-1514

15. Lens M, Bataille V (2008) Melanoma in relation to reproductive and hormonal factors in women: current review on controversial issues. Cancer Causes Control 19(5):437-442

16. Karagas MR, Zens MS, Stukel TA et al (2006) Pregnancy history and incidence of melanoma in women: a pooled analysis. Cancer Causes Control 17(1):11-19

17. Euvrard S, Kanitakis J, Claudy A (2003) Skin cancers after organ transplantation. N Engl J Med 348(17):1681-1691

18. Noller KL, Blair PB, O'Brien PC et al (1988) Increased occurrence of autoimmune disease among women exposed in utero to diethylstilbestrol. Fertil Steril 49:1080-1082

19. Burke L, Segall-Blank M, Lorenzo C, Dynesius-Trentham R, Trentham D, Mortola JF (2001) Altered immune response in adult women exposed to diethylstilbestrol in utero. Am J Obstet Gynecol 185(1):78-81

20. Ways SC, Mortola JF, Zvaifler NJ, Weiss RJ, Yen SS (1987) Alterations in immune responsiveness in women exposed to diethylstilbestrol in utero. Fertil Steril 48(2):193-197

21. Verloop J, Rookus MA, van Leeuwen FE (2000) Prevalence of gynecologic cancer in women exposed to diethylstilbestrol in utero. N Engl J Med 342(24):1838-1839

22. Hatch EE, Palmer JR, Titus-Ernstoff L et al (1998) Cancer risk in women exposed to diethylstilbestrol in utero. JAMA 280(7):630 634

23. Hatch EE, Herbst AL, Hoover RN et al (2001) Incidence of squamous neoplasia of the cervix and vagina in women exposed prenatally to diethylstilbestrol (United States). Cancer Causes Control 12(9):837-845

24. Klip H, Burger CW, de Kraker J, van Leeuwen FE (2001) Risk of cancer in the offspring of women who underwent ovarian stimulation for IVF. Hum Reprod 16(11):2451-2458 